\title{
Towards the cosmetic application of Passiflora coccinea (Aubl.): antioxidant activity and photo protective capacity of the methanolic and glycolic leaf extracts
}

\author{
Gisláine Correa da Silva1, Marcos José Salvador², Carla Beatriz Grespan Bottoli®*1
}

${ }^{1}$ Institute of Chemistry, University of Campinas (Unicamp), Campinas, São Paulo, Brazil, ${ }^{2}$ Department of Plant Biology, Institute of Biology, PPG BTPB, Pharmacy Course, University of Campinas (Unicamp), Campinas, São Paulo, Brazil

\begin{abstract}
The present study aimed at the evaluation of Passiflora coccinea (Aubl.) antioxidant and photo protective in vitro activities, looking forward to their application as antiaging or sunscreen agents in cosmetic formulations. Methanolic and glycolic leaf extracts were prepared by three methods: ultrasound assisted extraction (UAE, $30 \mathrm{~min}$.), maceration at room temperature $\left(72 \mathrm{~h}\right.$ ) and maceration at $30{ }^{\circ} \mathrm{C}$ $(72 \mathrm{~h})$. The antioxidant activities of the extracts were measured by DPPH and ORAC-FL assays and they were incorporated into a cosmetic emulsion to have their sun protection factor (SPF) measured spectrophotometricaly. The antioxidant activity of the emulsions were measured by DPPH and ORAC as well. C-glycosyl-flavones were identified in the extracts by ESI-MS/MS, in comparision with standards. The UAE methanolic extract and the maceration at $30^{\circ} \mathrm{C}$ glycolic extract were submmited to HPLC-DAD analysis and isovitexin was quantifyed in both by a validated method. The methanolic extract antioxidant activity was independent of the extraction method, higher than reported for other species of Passiflora and detectable when incorporated into the emulsion formulation. Maceration at $30^{\circ} \mathrm{C}$ was the most suitable method for glycolic extraction and its antioxidant activity was lower than the value presented by the methanolic extracts. None of the extracts exhibited a SPF value. Isovitexin in the UAE methanolic extract was 12.67 times higher than the most active glycolic extract, aside of their similar chromatographic profiles. Although a SPF value was not detected, the results indicate that $P$. coccinea can be a potential new source of antioxidants for topical antiaging formulations.
\end{abstract}

Keywords: Passiflora coccinea. Emulsion. Antioxidant. SPF. Isovitexin. HPLC-DAD.

\section{LIST OF ABBREVIATIONS}

AAPH: 2,2'-Azobis (2-amidinopropane) dihydrochloride ACN: Acetonitrile

AUC: Area Under Curve

DMSO: Dimethyl Sulphoxide

DPPH: 2,2-diphenyl-1-picrylhydrazyl radical

$\mathrm{EC}_{50}$ : Half maximal effective concentration

ESI-MS/MS: Electrospray Ionization Mass Spectrometry HPLC-DAD: High Performance Liquid Chromatography coupled to a Diode Array Detector

LOD: Limit of Detection

LOQ: Limit of Quantification

$\mathrm{MeOH}$ : Methanol

\footnotetext{
*Correspondence: C. B. G. Bottoli. Instituto de Química, Universidade Estadual de Campinas (Unicamp), Campinas, São Paulo, Brazil. E-mail: carlab@iqm.unicamp.br
}

ORAC-FL: Oxygen Radical Absorbance Capacity fluoresceine

PPG: Propylene glycol

ROS: Reactive Oxygen Species

SPE: Solid Phase Extraction

SPF:Sun Protection Factor

THF: Tetrahydrofuran

UAE: Ultrasound Assisted Extraction

UV: Ultraviolet Radiation

UVB: Ultraviolet Radiation at 320-280 nm

\section{INTRODUCTION}

Passiflora is one of the 27 genera inside Passifloraceae family. Some Passiflora species such as $P$. edulis, $P$. alata and $P$. incarnata, are very popular by their fruits and leaves, being used in folk medicine and in different pharmaceutical preparations mainly as sedatives 
and anxiolytics (Müller et al., 2005; Reginatto et al., 2006; Rudinicki et al., 2007; Zeraik et al., 2010a; Zeraik et al., 2010b). Great part of the data about Passiflora genus phytochemistry focus on their effects on the central nervous system, but the genus can provide a wide range of bioactive compounds for different applications. Passiflora leaves are a source of alkaloids, saponins, cyanogenic compounds and, mainly, polyphenols (Zeraik et al., 2010b; Silva, Bottoli, 2015).

C-glycosyl-flavones derived from apigenin and luteolin are the main polyphenols found in Passiflora leaves. Among various functions, polyphenols act against harms caused by the ultraviolet (UV) radiation in plants and, for this reason, they may be potentially useful for human skin photo protection as well. In fact, the basic structure of polyphenols is favorable for UV absorption in the same way organic sunscreens, such as cinammates and salicylates, act on the skin. In this sense, Velasco et al. (2008) studied the behavior of $P$. incarnata dry extract in a formulation containing an organic and an inorganic filter, showing that the association was positive in enhancing the spectrum of sun protection and, thus, confirming the potential cosmetic application of the genus (Müller et al., 2005; Dahuan, Dahuan, Sharma, 2004; Velasco et al., 2008).

On the other hand, it is widely well known that polyphenols present antioxidant activity through different pathways, such as reducing agent, hydrogen donor, singlet oxygen quencher and metal chelator (Ignat, Volf, Popa, 2011). It is important to highlight that, besides the employment of organic and inorganic filters in sunscreens formulations, another established approach in skin care is the use of topical antioxidants, once excessive UV radiation on human skin can lead to the overproduction of reactive oxygen species (ROS). ROS are free radicals which can react unespecifically with a variety of cellular constituents: when produced in high levels, several effects such as skin photo ageing and skin cancer may occur (Gonzales, Fernandes-Lorente, Gilaberte-Calzada, 2008; Afaq, 2011; Barreira et al., 2013). There have been evidences that polyphenolic extracts are potentially beneficial as active ingredients in topical products for both the prevention and the treatment of damages caused by UV (Zillich et al., 2017). The in vitro antioxidant activities of $P$. edulis aqueous and $40 \%$ ethanol leaf extracts (Ferreres et al., 2007; Rudinicki et al., 2007), P. alata $40 \%$ ethanol leaf extract (Rudinicki et al., 2007) and P. incarnata 70\% ethanol leaf extract (Masteikova et al., 2008) have been reported, and these data indicate that the genus is a potential source of antioxidant ingredients to be explored.
Methanol and ethanol are the most commonly used solvents in polyphenol extraction methods (Ignat, Volf, Popa, 2011; Stalikas, 2007). However, plant glycolic extracts are class of cosmetic raw materials prepared with glycerol or propylene glycol and they are commonly used in topical formulations. Reports on the properties and compositions of these type of extracts are rare in literarure, making it difficult to ascertain that what is scientifically proven corresponds to what is commonly formulated and consumed in terms of performance. In general, plant extracts can be prepared by conventional extraction methods, such as infusion, reflux and percolation. Novel techniques like microwave-assisted extraction (Ignat, Volf, Popa, 2011; Xiao, Han, Shi, 2008) and ultrasound-assisted extraction (Huang et al., 2009) of Passiflora polyphenols have been successfully described.

Therefore, considering the previous knowledge about other species of Passiflora and their potential as direct photo protectors or as antioxidants, the present study aimed at the the comparison of the in vitro photo protective and antioxidant activities of glycolic and methanolic extracts of Passiflora coccinea (Aubl.), a lianous species found in the Amazon region of South America with few reports about (Correa, 1984). The glycolic and methanolic leaf extracts of $P$. coccinea were prepared by three distinct methods of extraction: ultrasound-assisted extraction (UAE), considered as a novel technique, and maceration, which is a classic method, at room temperature and at $30^{\circ} \mathrm{C}$, in order to establish if temperature oscilation could influence the performance of the extracts.

\section{MATERIAL AND METHODS}

\section{Chemicals}

Vitexin and isovitexin (purity $\geq 96 \%$ ) were purchased from Sigma-Aldrich (St. Louis, MO, USA). 2"-O- $\beta-D-$ glucopyranosyl-vitexin had been previously isolated from Alternanthera tenella (Colla) (Salvador et al., 2006). Methanol $(\mathrm{MeOH})$, acetonitrile $(\mathrm{ACN})$ and tetrahydrofuran (THF) HPLC grade from Tedia (Fairfild, OH, USA) were used. Propylene glycol from Ecibra (Santo Amaro, SP, Brazil), ethanol and phosphoric acid from Synth (Diadema, SP, Brazil) were of analytical grade. Water was purified in a Milli-Q system from Millipore (Bedford, MA, USA). For the antioxidant assays, 2,2-diphenyl-1-picrylhydrazyl (DPPH), 2,2'-Azobis (2-amidinopropane) dihydrochloride (AAPH), Rutin Dihidrate, Trolox (6-Hydroxy-2,5,7,8tetramethylchroman-2-carboxylic acid), monobasic dipotassium phosphate, dibasic sodium phosphate, dimethyl sulphoxide (DMSO), all from Sigma Aldrich (St. 
Louis, MO, USA), and fluorescein from Fluka (St. Louis, MO, USA), were used. Topical emulsion formulation was ceded by Consulfarma (Campinas, SP, Brazil).

\section{Plant material}

Leaves of $P$. coccinea (Aubl.) were collected at the Biology Institute of University of Campinas (UNICAMP, Brazil). Voucher material was deposited at the herbarium of the same institute under the register code UEC 94134. The material was kept in an oven at $70^{\circ} \mathrm{C}$ for 10 minutes, then dried at $60^{\circ} \mathrm{C}$ until constant weight and then powdered. The powder was stored in a glass flask, away from the light and under refrigeration.

\section{Extraction procedures}

\section{Ultrasound-assisted extraction (UAE)}

In glass flasks with screw caps, $2.00 \mathrm{~g}$ of $P$. coccinea leaf powder, $40.0 \mathrm{~mL}$ of methanol (methanolic extract) or $40.0 \mathrm{~mL}$ of propylene glycol (glycolic extract) were added. The flasks were placed in an ultrasonic bath model UltraCleaner 1400, Unique (Indaiatuba, SP, Brazil), with an internal dimension of $240 \times 137 \times 100 \mathrm{~mm}$ and potency of $40 \mathrm{kHz}$, for 30 minutes. Methanolic and glycolic extracts were submitted to centrifugation at $3000 \mathrm{rpm}$ (I 206BL Fanem Baby centrifuge (São Paulo, SP, Brazil)) and the supernatants were collected. After withdrawing $1.0 \mathrm{~mL}$ for mass spectrometry analysis, the solvent of methanolic extracts were evaporated with a nitrogen gas flux and stocked under refrigeration, while glycolic extracts were stored under the same condition with no previous solvent evaporation. The extraction with each solvent was carried out in triplicate.

\section{Maceration}

UAE extraction was carried out also with $2.00 \mathrm{~g}$ of $P$. coccinea leaf powder and $40.0 \mathrm{~mL}$ of the extraction solvent (methanol or propylene glycol). The powder was macerated for $72 \mathrm{~h}$ at room temperature and the post treatment of the extracts were the same as described above. Maceration was done in triplicate with both methanol and propylene glycol.

\section{Controlled temperature maceration $\left(30^{\circ} \mathrm{C}\right)$}

The flasks containing $2.00 \mathrm{~g}$ of $P$. coccinea leaf powder and $40.0 \mathrm{~mL}$ of the extraction solvent were immerged in a water bath with controlled temperature $\left(30^{\circ} \mathrm{C}\right)$. Maceration proceeded for $72 \mathrm{~h}$ in triplicate with each solvent and the post treatment of the extracts were the same as described above.

\section{Topic emulsion formulations}

The methanolic and glycolic extracts were incorporated to a moisturizing topical emulsion formulation (Table I). The glycolic extracts were added at $10.0 \%(\mathrm{w} / \mathrm{w})$ for the test, while the methanolic ones were mixed to the topical emulsion formulation at the proportion of $1.0 \%$ (w/w) due to their dark green color, which could lead to extremely dark and visually not appealing formulations if used in high concentrations.

TABLE I-Moisturizing topical emulsion formulation composition

\begin{tabular}{lc}
\hline INCI* & Quantity (w/w) \\
\hline Glycerin & 0.5 \\
Ammoniun Acryloyldimethyltaurate / VP & 0.7 \\
Copolymer & \\
Tribehenin PEG-20 Esters & 2.5 \\
Sweet Almond Oil & 3.0 \\
Tetradibutyl Pentaerithrityl & 0.1 \\
Hydroxyhydrocinnamate & \\
Cyclopentasiloxane & 6.0 \\
Phenoxyethanol & 0.4 \\
Aqua & \\
\hline
\end{tabular}

*International Nomenclature of Cosmetic Ingredients

In order to check the stability of the formulations, an aliquot of $1.0 \mathrm{~g}$ of each emulsion was centrifuged at $3000 \mathrm{rpm}$ for $30 \mathrm{~min}$ and a visual inspection of possible phase separation before and after the test was proceeded (Brasil, 2004).

\section{Antioxidant activity and photo protective capacity assays}

\section{$\mathrm{DPPH}$}

All the assays were done according to Mensor et al. (2001) adapted to a 96 well microplate. Briefly, $10.0 \mu \mathrm{L}$ of stock ethanolic extract solutions were pipetted in a 96-well microplate in triplicate, with the further addition of $190.0 \mu \mathrm{L}$ of ethanol and $80.0 \mu \mathrm{L}$ of a $0.30 \mathrm{mmol} \mathrm{L}^{-1} \mathrm{DPPH}$ ethanol solution. Final concentrations of the methanolic extracts in the microplate were in the range of 6.2 to $200.0 \mu \mathrm{g} \mathrm{mL}^{-1}$, while the glycolic extracts were evaluated in the range of 25.0 to $800.0 \mu \mathrm{g} \mathrm{mL}^{-1}$ and the emulsion formulations were tested from 50.0 to $1600.0 \mu \mathrm{g} \mathrm{mL}^{-1}$. Rutin was used as a positive control, $80 \mu \mathrm{L}$ of DPPH 0.30 mmol L-1 in $200.0 \mu \mathrm{L}$ of ethanol were used as negative control and ethanol served as a blank.

The reactions were monitored at $517 \mathrm{~nm}$ in a 
BioTek Sinergy 2 microplate reader (Winooski, VT, USA) for 50 minutes and the percentage of DPPH reduction was measured in triplicate for all the extracts and emulsions. The $\mathrm{EC}_{50}$ values were obtained from hyperbolic regressions calculated by Microcal Origin 6.0, OriginLab Corp. (Northampton, MA, USA).

\section{ORAC-FL}

ORAC-FL (Oxygen radical absorbance capacity) assay was based on Salvador et al. (2006). To $1.0 \mathrm{mg}$ of the extracts, $20.0 \mu \mathrm{L}$ of DMSO were added. The stock solution was diluted 100.0, 500.0, 1000.0, 5000.0 and 10000.0 times with a $\mathrm{pH} 7.00$ phosphate buffer. Test solutions $(50.0 \mu \mathrm{L})$ and fluorescein $(100.0 \mu \mathrm{L}$, final concentration of $\left.1.245 \mu \mathrm{g} \mathrm{mL}^{-1}\right)$ were pippeted into the microplate. AAPH solution $\left(50.0 \mu \mathrm{L}\right.$, final concentration of $\left.81.8 \mu \mathrm{g} \mathrm{mL}^{-1}\right)$ was added and the plate was immediately placed in a Sinergy 2, BioTek microplate reader (Winooski, VT, USA) previously heated at $37^{\circ} \mathrm{C}$. Fluorescence (excitation $\lambda=485 \mathrm{~nm}$ and emission $\lambda=528 \mathrm{~nm}$ ) was recorded every two minutes for $70 \mathrm{~min}$. Fluorescein plus AAPH in phosphate buffer was used as a blank and six solutions of Trolox (3.12, 6.25, 12.5, 25.0 and $50.0 \mu \mathrm{mol} \mathrm{L}^{-1}$, final concentrations) were used for calibration. All the extracts were assayed in triplicate and the results were expressed in terms of $\mu \mathrm{mol}$ of Trolox equivalents (TE) per gram of extract $\left(\mu \mathrm{mol} \mathrm{TE} \mathrm{g}{ }^{-1}\right)$.

\section{In vitro photo protective assay}

In order to check the ability of the extracts in absorbing in the UV region, spectra of ethanolic solutions of the methanolic extracts $\left(1 \mathrm{mg} \mathrm{mL}^{-1}\right)$ and of the glycolic extracts $\left(10.0 \mathrm{mg} \mathrm{mL}^{-1}\right)$ were obtained in a Hewlett Packard 8453 spectrophotometer (Palo Alto, CA, USA), from 100 to $400 \mathrm{~nm}$. The assay was carried out in a quartz cuvette with a $1.0 \mathrm{~cm}$ of optical path.

The sun protection factor (SPF) of the emulsions was measured according to Mansur et al. (1986) with some adaptations. Briefly, the topical emulsion formulations containing the extracts were diluted in ethanol (final concentration: $0.2 \mathrm{mg} \mathrm{mL}^{-1}$ ) for the assay. A formula containing $8.0 \%$ of benzophenone-3, with theoretical SPF of 11.5 (Basf sunscreen simulator, 2017), was used as a standard.

\section{Statistical analysis of the results}

One-way analysis of variance (ANOVA), followed by Tukey's test $(p \leq 0.05)$ was used for the comparison of three means, while Student's t-test $(\mathrm{p} \leq 0.05)$ was used to compare two different means.

\section{Chemical analyses of the extracts}

\section{Identification of C-glycosyl-flavones by Electrospray Ionization Mass Spectrometry (ESI-MS/MS)}

Ten microliters of each methanolic and glycolic extract were dissolved in $1.0 \mathrm{~mL}$ of $\mathrm{ACN}: \mathrm{H}_{2} \mathrm{O}: \mathrm{NH}_{4} \mathrm{OH}$, $(80: 20: 0.1, \mathrm{v} / \mathrm{v} / \mathrm{v})$. The solutions were directly infused in a Waters Quattro Micro-API triple quadrupole tandem mass spectrometer (Manchester, UK) with an ESI source operating in negative ionization mode (ESI(-)-MS). Spectral data were recorded from 150 to $1000 \mathrm{~m} / \mathrm{z}$ ratio and the analysis were carried out in a $100 \mu \mathrm{L} \mathrm{min}^{-1}$ flow rate. Optimal voltages of capillary and cone were of $2.5 \mathrm{kV}$ and $30.0 \mathrm{~V}$, respectively, and a $800 \mathrm{~L} \mathrm{~h}^{-1}$ nitrogen gas flux was used for desolvation. The temperatures of the source and desolvation gas were 150 and $400^{\circ} \mathrm{C}$, respectively. The ions of interest were fragmented with argon at $120 \mathrm{~L} \mathrm{~h}^{-1}$ and collision energy of $20.0 \mathrm{~V}$. The spectra were compared to the profiles of standard polyphenolic compounds.

Characterization of the extracts by High Performance Liquid Chromatography coupled to a Diode Array Detector (HPLC-DAD)

The most suitable methanolic and glycolic extracts, elected in terms of the extraction methods and assays results, were cleaned up by solid phase extraction (SPE) on Supelclean LC18 cartridges (Supelco, Sigma Aldrich, St. Louis, MO, USA) pre-conditioned with $5.0 \mathrm{~mL}$ of methanol HPLC-grade and $5.0 \mathrm{~mL}$ of $\mathrm{H}_{2} \mathrm{O}: \mathrm{H}_{3} \mathrm{PO}_{4}$, $\mathrm{pH} 2.65$. Five milligrams of the most suitable methanolic extract were diluted to $500 \mu \mathrm{L}$ of methanol and the phenolic fraction was eluted with $2 \mathrm{~mL}$ of $\mathrm{MeOH}: \mathrm{H}_{2} \mathrm{O}$, pH $2.65(60: 40, v / v)$. The eluate was concentrated under nitrogen gas flux and the residue was dissolved to $1.0 \mathrm{~mL}$ with methanol prior to HPLC-DAD injection. Similar procedure was adopted to the most suitable glycolic extract, to which $200 \mu \mathrm{L}$ were diluted to $500 \mu \mathrm{L}$ with methanol and the phenolic fraction was reconstituted to $500 \mu \mathrm{L}$ with methanol before the chromatographic separation.

HPLC-DAD analyses were performed with a Shimadzu Proeminence LC20AT liquid chromatograph (Nakagyoku, Kyoto, Japan) with a Shimadzu Proeminence SPD-M20A diode array detector. Separations were done in a Merck (Darmstadt, Germany) LiChrospher RP-18e column ( $250 \mathrm{~mm} \times 4 \mathrm{~mm}$ i.d. $\times 5 \mu \mathrm{m})$, with a mobile phase constituted of $\mathrm{H}_{2} \mathrm{O}: \mathrm{H}_{3} \mathrm{PO}_{4}(\mathrm{pH}$ 2.65) (A) and ACN-THF 95:5 (v/v) (B) in the following gradient program: 0-11 min, 5-18\% B; 11-35 min, 18-19\% B; 35-36 min, $19-5 \% \mathrm{~B}$ and $37 \mathrm{~min}, 5 \% \mathrm{~B}$. Flow rate was set to $1.0 \mathrm{~mL} \mathrm{~min}^{-1}$ and the chromatograms were monitored at $330 \mathrm{~nm}$. 


\section{Quantitative HPLC-DAD analysis and method validation}

Among the identified compounds, isovitexin was elected for the quantitative comparison between the most suitable methanolic and glycolic extracts due to its high signal in the chromatogram and to its commercial availability. A slight modification in the gradient program was done in order to improve its resolution for a more liable quantification. Therefore, samples were eluted with a mobile phase composed of $\mathrm{H}_{2} \mathrm{O}-\mathrm{H}_{3} \mathrm{PO}_{4}(\mathrm{pH} 2.65)$ (A) and ACN-THF 95:5 (v/v) (B), with the following gradient: 0-15 min, 5-16\% B; 15-37 min, 16-17\% B; 37-39 min, $17-5 \% \mathrm{~B}$ and $39-40 \mathrm{~min}, 5 \% \mathrm{~B}$. Flow rate was set to $1 \mathrm{~mL}$ $\mathrm{min}^{-1}$ and the detection was done at $330 \mathrm{~nm}$.

The quantification of isovitexin was done by the standard addition method. For the methanolic extract, $3.0 \mathrm{mg}$ samples were weighed into $2.0 \mathrm{ml}$ volumetric flasks. Samples were fortified with the appropriate volume of a $500 \mathrm{mg} \mathrm{L}^{-1}$ standard isovitexin solution to achieve final concentrations of 1.0, 5.0, 10.0, 15.0 and $20.0 \mathrm{mg} \mathrm{L}^{-1}$, and the volumes of the solutions were adjusted to $2.0 \mathrm{~mL}$ with methanol (HPLC grade). A similar procedure was done with the glycolic extract, by fortifying $1.0 \mathrm{~mL}$ of the extract in $2.0 \mathrm{~mL}$ flasks to the same levels. The fortified solutions of both extracts were cleaned up using Supelclean LC-18 solid phase extraction (SPE) cartridges from SupelcoSigma Aldrich (USA) in a SPE manifold from Phenomenex (USA). The cartridges were pre conditioned with $5.0 \mathrm{ml}$ of methanol (HPLC grade), followed by $5.0 \mathrm{~mL}$ of water acidified with $\mathrm{H}_{3} \mathrm{PO}_{4}$ to $\mathrm{pH} 2.65$. The samples were eluted with $2.0 \mathrm{~mL}$ of a mixture of methanol and $\mathrm{H}_{2} \mathrm{O}: \mathrm{H}_{3} \mathrm{PO}_{4}$ $(\mathrm{pH} 2.65)(60: 40, \mathrm{v} / \mathrm{v})$. A curve of standard isovitexin in methanol at the same levels was also constructed.

The Figures of Merit were validated according to the International Conference on Harmonization (ICH) of Technical Requirements for Registration of Pharmaceuticals for Human Use (2005). The selectivity of the method was evaluated by comparison of the retention times of standard isovitexin and its corresponding peak in the extracts. It was also verified by the fortification of the samples for the construction of the analytical curves and by the peak purity, checking the similarities of the peak spectral data from 200 to $800 \mathrm{~nm}$ at the beginning, the top and the tail of the peak. The matrix effect was evaluated according to Economou et al. (2009). The significance of the matrix effect was evaluated by a Student t-test at $95 \%$ of confidence by comparison of the angular coefficients of the analytical curves of the extracts and standard isovitexin curve.

The linearity of the analytical curves were evaluated by the correlation coefficients and by analysis of variance
(ANOVA) with $p<0.05$. The limits of detection (LOD) and quantification (LOQ) of the method were determined by signal-to-noise ratios of $3: 1$ and 10:1, respectively. Precision was determined by repeatability tests at low (1.0 mg L-1), medium (10.0 $\left.\mathrm{mg} \mathrm{L}^{-1}\right)$ and high $\left(20.0 \mathrm{mg} \mathrm{L}^{-1}\right)$ concentrations by using the same process of sample fortification and SPE previously described: the assay was done in triplicate for each concentration. The accuracy of the method was checked by the recovery assay, in triplicate, at low $\left(1.0 \mathrm{mg} \mathrm{L}^{-1}\right)$, medium $\left(10.0 \mathrm{mg} \mathrm{L}^{-1}\right)$ and high $\left(20.0 \mathrm{mg} \mathrm{L}^{-1}\right)$ concentrations. The recovery was calculated by the following equation (Equation 1),

$$
\operatorname{Recovery}(\%)=\frac{C f-C i}{C a}
$$

where $\mathrm{Cf}$ is the final concentration after fortification, $\mathrm{Ci}$ is the initial concentration of isovitexin in the sample and $\mathrm{Ca}$ is the concentration of standard added in the fortification process. Finally, the extraction efficiency of the SPE process was evaluated according to Siqueira et al. (2009) at the low (1.0 mg L-1) and high concentrations $\left(20.0 \mathrm{mg} \mathrm{L}^{-1}\right)$, by comparison of samples fortified prior to and after the extraction process with the following equation (Equation 2)

$$
E E(\%)=\frac{A b}{A a} .100
$$

where $\mathrm{Ab}$ is the isovitexin peak area of the sample fortified before the SPE process and Aa is the area of isovitexin peak of the sample fortified after the extraction procedure.

\section{RESULTS AND DISCUSSION}

\section{Antioxidant activity}

All the methanolic extracts presented antioxidant activity in the DPPH assay. For the calculation of $\mathrm{EC}_{50}$ values, the percentages of radical reduction at $40 \mathrm{~min}$ of reaction were considered, since stabilization was observed at this time (Figure 1).

The $\mathrm{EC}_{50}$ values for methanol UAE, maceration and controlled temperature maceration were $13 \pm 2,11 \pm 1$ and $12 \pm 1 \mu \mathrm{g} \mathrm{mL}^{-1}$, respectively. Regression lines presented good coefficient of determination $\left(\mathrm{r}^{2}>0.90\right)$ and the $\mathrm{EC}_{50}$ values were equal at $95 \%$ of significance, showing that the extraction method did not influence the antioxidant activity of the methanolic extracts of $P$. coccinea. In this case, UAE showed an advantage over the other methods due to its lower extracton time and, therefore, it was chosen as the best method among the three tested in the present work for this solvent. These $\mathrm{EC}_{50}$ values are lower than the ones reported for Passiflora loefgrenii Vitta 80\% 
methanol leaf extract $\left(350 \mu \mathrm{g} \mathrm{mL}^{-1}\right)$, for Passiflora wilsonii Hemsl. extracts prepared with different solvents $\left(\mathrm{EC}_{50}\right.$ arround $100 \mu \mathrm{g} \mathrm{mL}^{-1}$ ) and for Passiflora quadrangularis, P. maliformis and P. edulis leaf $\left(\mathrm{EC}_{50}\right.$ range from 456.9 to $\left.3423.8 \mu \mathrm{g} \mathrm{mL}^{-1}\right)$ and stem extracts $\left(\mathrm{EC}_{50}\right.$ range from 313.7 to $\left.2137.2 \mu \mathrm{g} \mathrm{mL}^{-1}\right)$, indicating that $P$. coccinea methanolic extracts have a great antioxidant capacity (Argentieri et al., 2015; Jiang et al., 2015; Ramaiya, Bujang, Zakaria, 2014).

This behavior was not repeated by the glicolic extracts, for which the $\mathrm{EC}_{50}$ could not be calculated. At the concentration of $800 \mu \mathrm{g} \mathrm{mL}^{-1}$, ultrassound assisted extract did not show any activity in the assay, but maceration extract was able to reduce $27 \pm 3 \%$ and controlled temperature maceration extract reduced $33 \pm 1 \%$ of
DPPH radical. Beyond the lower antioxidant activity in relaton to the methanolic extracts, the glycolic extracts were influenced by the extraction method. The results of the reduction percentage for both maceration extractions are different at $95 \%$ of significance and, thus, controlled temperature maceration for $72 \mathrm{~h}$ produced the most antioxidant glycolic extract.

The performances of methanolic and glycolic extracts were also diffrerent in ORAC-FL test, in agreement with the results observed in DPPH assays. The ORAC values for the methanolic extracts were of $3177 \pm 12 \mu \mathrm{mol} \mathrm{TE} \mathrm{g}{ }^{-1}$

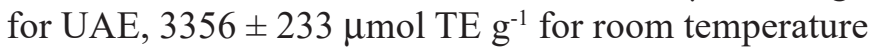
maceration and $3284 \pm 40 \mu \mathrm{mol} \mathrm{TE} \mathrm{g}^{-1}$ for $30{ }^{\circ} \mathrm{C}$ maceration. These values are higher than the one reported
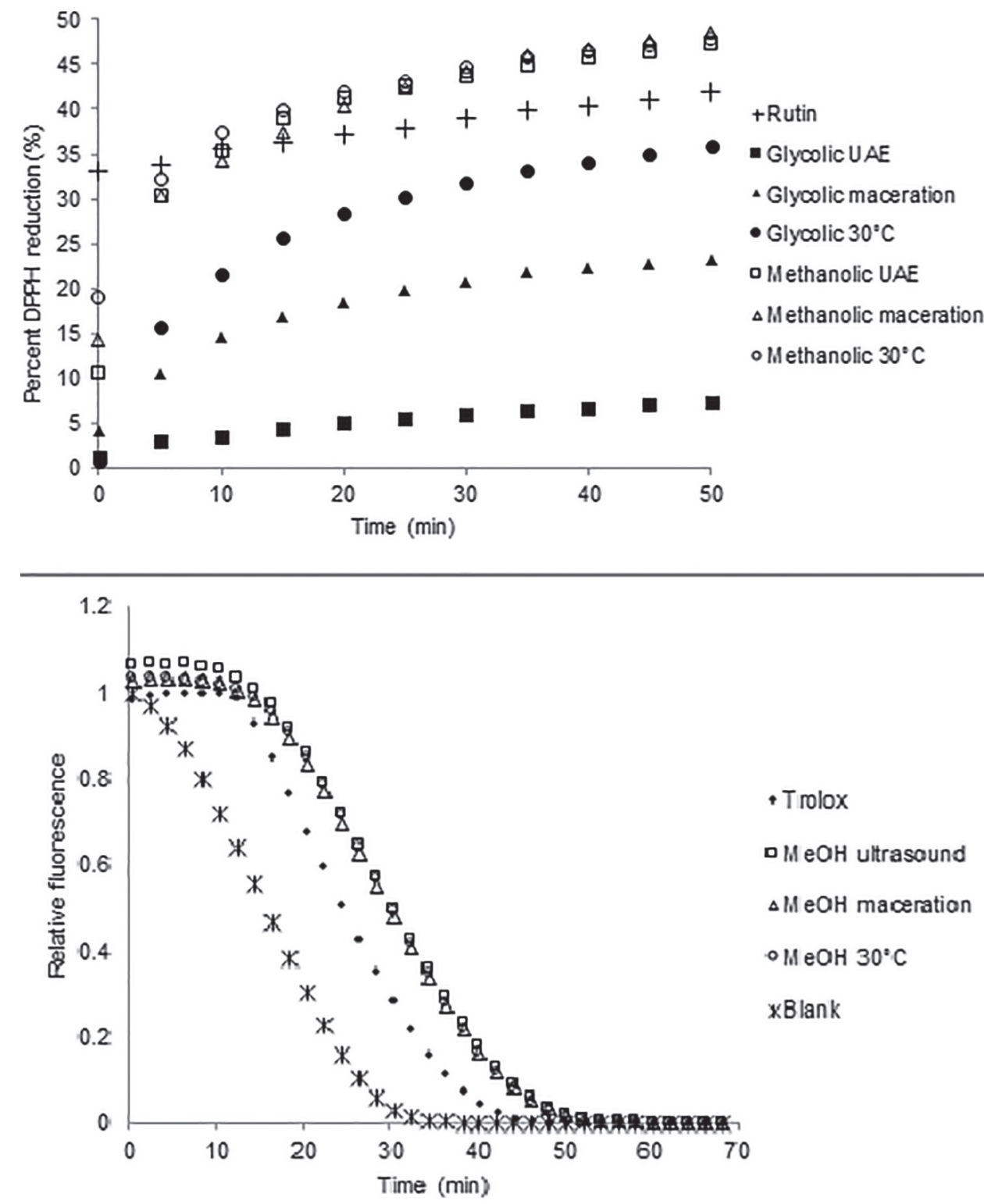

FIGURE 1 - Top: DPPH reaction kinetics. Extracts concentration: $12.5 \mu \mathrm{g} \mathrm{mL}^{-1}$. Rutin: $6.2 \mu \mathrm{g} \mathrm{mL}^{-1}$. MeOH: methanolic extract. PPG: glycolic extract. Bottom: Fluorescence decay of te methanolic extracts in ORAC-FL test. 
for $P$. edulis aqueous extract $\left(373 \pm 1.63 \mu \mathrm{mol} \mathrm{TE} \mathrm{g}^{-1}\right)$ (Silva et al., 2013). On the other hand, glycolic extracts did not show significant activity in this test. Figure 1B shows the curves of fluorescence decay for the methanolic extracts, in which the area under curve (AUC) of the extracts are quite similar among themselves and higher than the AUC of the Trolox reference, showing that these extracts were active in ORAC-FL test.

The efficiency of UAE with methanol and not with propylene glycol could be explained by the physical properties of these solvents: it is thought that ultrasound extraction occurs by a cavitational phenomena, in which solvent bubbles are formed by the propagation of pressure waves. The implosion of the bubbles causes micro-jets that result in surface erosion and in particle breakdown, enhancing extraction. Cavitational phenomena decreases with high vapor pressure and high surface tension solvents and this could explain the unsatisfactory antioxidant activity of the glycolic extract obtained by UAE, since propylene glycol has a high viscosity and a high boiling point $\left(180^{\circ} \mathrm{C}\right)$ in comparison to methanol and, therefore, a lower extraction power by this method (Vilkhu et al., 2008; Paniwynk et al., 2009).

Among the topical emulsions, only the formulation containing $P$. coccinea $1.0 \%$ (wt/wt) methanolic extracts showed measurable activity in the DPPH test. At the concentration of $1600 \mathrm{mg} \mathrm{mL}^{-1}$, UAE reduced $38 \pm 2 \%$, maceration at room temperature extract $40 \pm 2 \%$ and, maceration at $30^{\circ} \mathrm{C}, 36.3 \pm 0.9 \%$ of the $\mathrm{DPPH}$ radical. The formulations containing $P$. coccinea glycolic extracts showed no activity against DPPH. In the ORAC-FL test, the methanolic extracts topical emulsions showed similar activity of Trolox standard, while the formulations containing the $P$. coccinea glycolic extracts had no activity detected in this test.

\section{In vitro photo protective activity}

The UV spectra showed that both the methanolic and the glycolic $P$. coccinea extracts could absorb in the UVB region (320-280 nm). Therefore, the photo protective test was suitable for further investigation of the possibility of using $P$. coccinea extracts as direct sunscreens.

As the photo protective assay requires an emulsion as a substrate, the extracts were incorporated into a moisturizing topical emulsion formulation according to in Table I. All the emulsions remained visually stable after the centrifuge test, with no phase separation being observed. Therefore, all topical emulsions were evaluated in terms of their SPF, but none of them provided direct sunscreen properties, as shown in Figure 2. Only the standard 8\% (wt/wt) benzophenone-3 formulation could have its SPF calculated, scoring $9.3 \pm 0.2$. This value is close to the 11.5 predicted by Basf sunscreen simulator ${ }^{\mathrm{TM}}$. The moisturizing topical emulsion formulations containing either the methanolic or the glycolic extracts showed no direct sunscreen properties.

\section{Chemical analyses of the extracts}

As the main bioactive compounds described to Passiflora genus are C-glycosil-flavones derived from
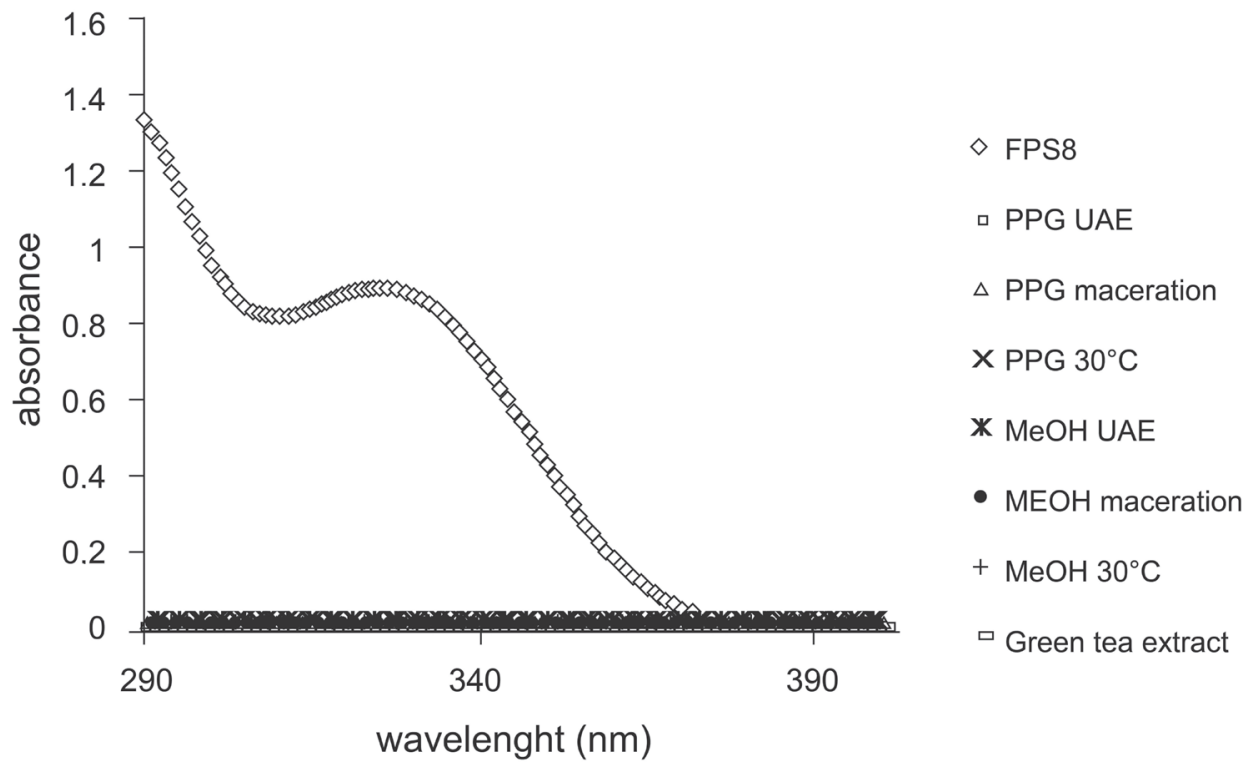

wavelenght $(\mathrm{nm})$

FIGURE 2 - UV absorption spectra of the topical emulsion formulations at $0.2 \mathrm{mg} \mathrm{mL}^{-1}$. FPS8: standard formulation. PPG: propylene glycolyc extracts. $\mathrm{MeOH}$ : methanolic extracts. 
apigenin and luteolin (Müller et al., 2005), direct infusion in the ESI-MS system could provide a chemical fingerprint of the extracts and the identification of some compounds of this class by ESI-MS/MS. In all extracts spectra, m/z 431 and 593 were found, which could correspond to the possible presence of the isomer pair vitexin / isovitexin and an O-glycosyl-C-glycosyl apigenin derivate, respectively. Up to the present moment, this class of polyphenols in Passiflora genus has been reported by Ferreres et al. (2007) in P. edulis water-methanol $(1: 1, \mathrm{v} / \mathrm{v})$ leaf extract obtained by sonication for $60 \mathrm{~min}$, who also highlighted the existence of a pro and an antioxidant effect of the lyophilised aqueous leaf extract of the same species, the latter being higher than the former one. Vitexin and isovitexin have been found in species like P. alata (Müller et al., 2005; Pereira, Yariwake, McCullagh,
2005) P. edulis (Ferreres et al., 2007; Pereira, Yariwake, McCullagh, 2005), P. caeruela (Pereira, Yariwake, McCullagh, 2005) and P. incarnata (Dahuan, Dahuan, Sharma, 2004; Masteikova et al., 2008). Masteikova and co-workers (2008) also compared the antioxidant activity of aqueous and $70 \%$ ethanolic $P$. incarnata leaf extracts, concluding that the latter extract is a more efficient free radical binder than the former. It was also stabilished that the strongest antioxidant activity among the investigated flavonoids were predetermined by vicenin, isovitexin and orientin.

Fragmentation of the $m / z 431$ ion of methanolic extract and the standards could not confirm the presence of either one or both of the vitexin isomers but could indicate that at least one of them was present in P. coccinea by the spectral similarity (Figure 3).
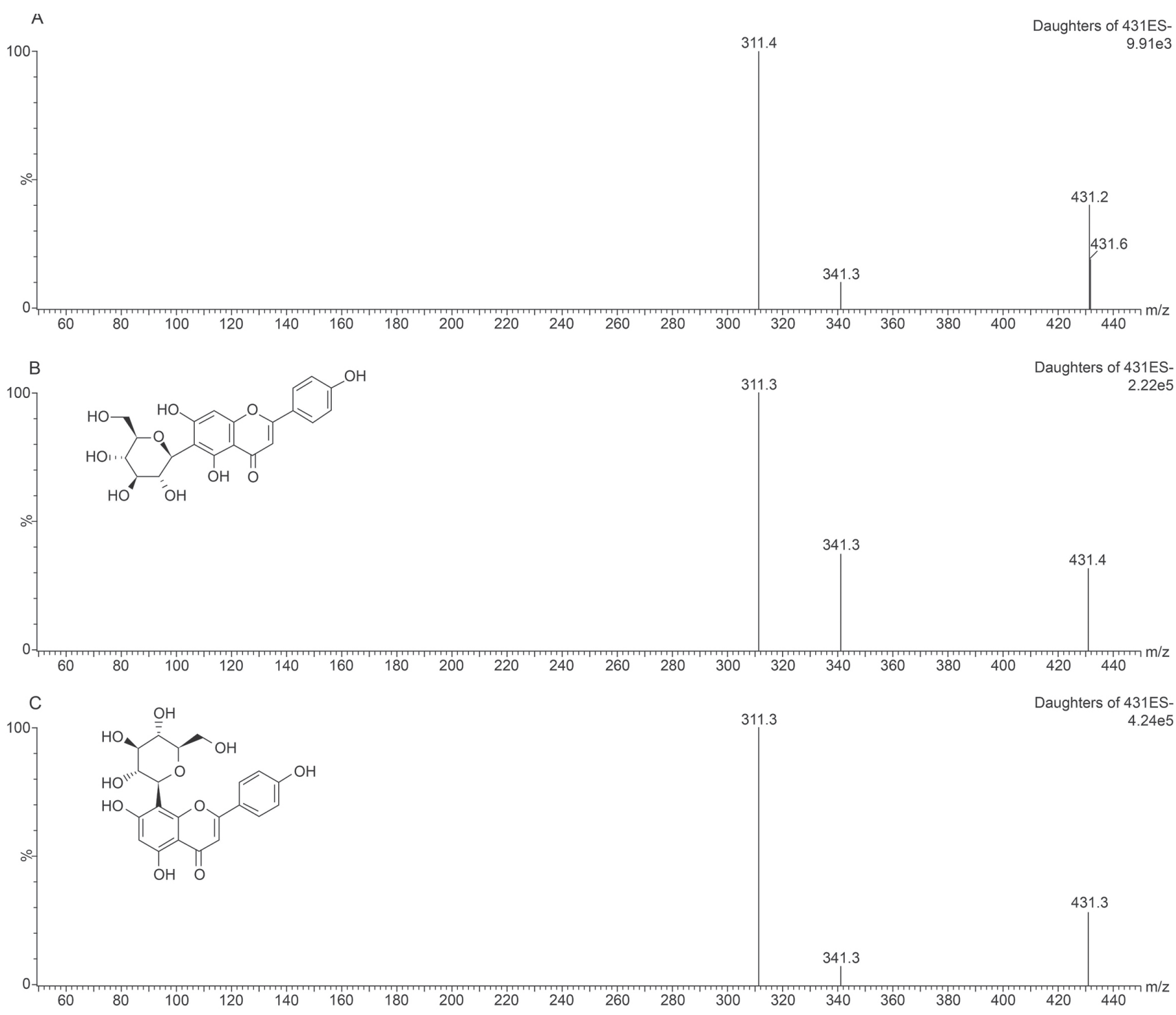

FIGURE 3 - ESI(-)-MS/MS. A) Fragmentation of peak $431 \mathrm{~m} / z$ of P. coccinea (Aubl.) methanolic extract. B) Fragmentation of isovitexin. C) Fragmentation of vitexin. For conditions, see material and methods. 
Differently of $\mathrm{m} / \mathrm{z} 431$ signal, fragmentation of $\mathrm{m} / \mathrm{z} 593$ peak could be compared to 2 "-O- $\beta$-Dglucopyranosyl-vitexin and the spectrum of the standard was very similar to the one found in the methanolic extract (Figure 4).

In order to confirm the presence of 2 "-O- $\beta$-Dglucopyranosyl-vitexin and to elucidate if the isomer pair vitexin-isovitexin was present in the extracts, a HPLCDAD separation method was developed with the standard compounds and the most suitable methanolic (UAE) and glycolic $\left(30^{\circ} \mathrm{C}\right.$ maceration) extracts were evaluated.

The presence of the mentioned flavonoids in $P$. coccinea was reaffirmed by HPLC-DAD. As shown in Figure 5, chromatograms of the most suitable glycolic and methanolic extracts were quite similar and vitexin, isovitexin and 2"-O- $\beta$-D-glucopyranosyl-vitexin were also found in both of them, proven by the similarity in the retention times, UV spectra and fortification of the extracts with the standard solutions. The chromatograms indicate that methanol and propylene glycol have similar selectivity to $P$. coccinea bioactive compounds.

Up to the present moment, the chemical compounds described in this species are the cyanogenic glycoside passicoccin (Spencer, Seigler, 1985), procyanidin derivatives, flavones-C-glycosides, flavones-8,7-di-O,Cglycosides and flavone-O-diglucoside (Sakalem, Negri,
Tabach, 2012). In the present work, vitexin, isovitexin and 2 "-O- $\beta$-D-glucopyranosyl-vitexin were detected in both types of $P$. coccinea extracts.

\section{Quantitative HPLC Analysis}

A HPLC-DAD method was validated for isovitexin quantification in order to enable a chemical comparison between the methanolic and the glycolic extracts. As mentioned before, isovitexin was elected for the quantitative analysis due to its high signal (Figure 5) and to its commercial availability. The isovitexin peak provided enough resolution (higher than 1.5) in the chromatogram for its quantification in the extracts, in spite of the complexity of the matrixes analyzed and, thus, analytical curves for both extracts were constructed. Figure 6 shows the chromatograms and the spectral purity of isovitexin peak of both extracts. It can be seen that great spectral similarity at the beginning, top and end of the peak was achieved and, thus, the method was considered selective for this compound.

The LOD and LOQ of the instrument were of 0.12 and $0.25 \mathrm{mg} \mathrm{L}^{-1}$, respectively, showing that the working range used for isovitexin quantification was adequate. Correlation coefficients of the three curves were higher than 0.99 and the adjustment of the linear models were

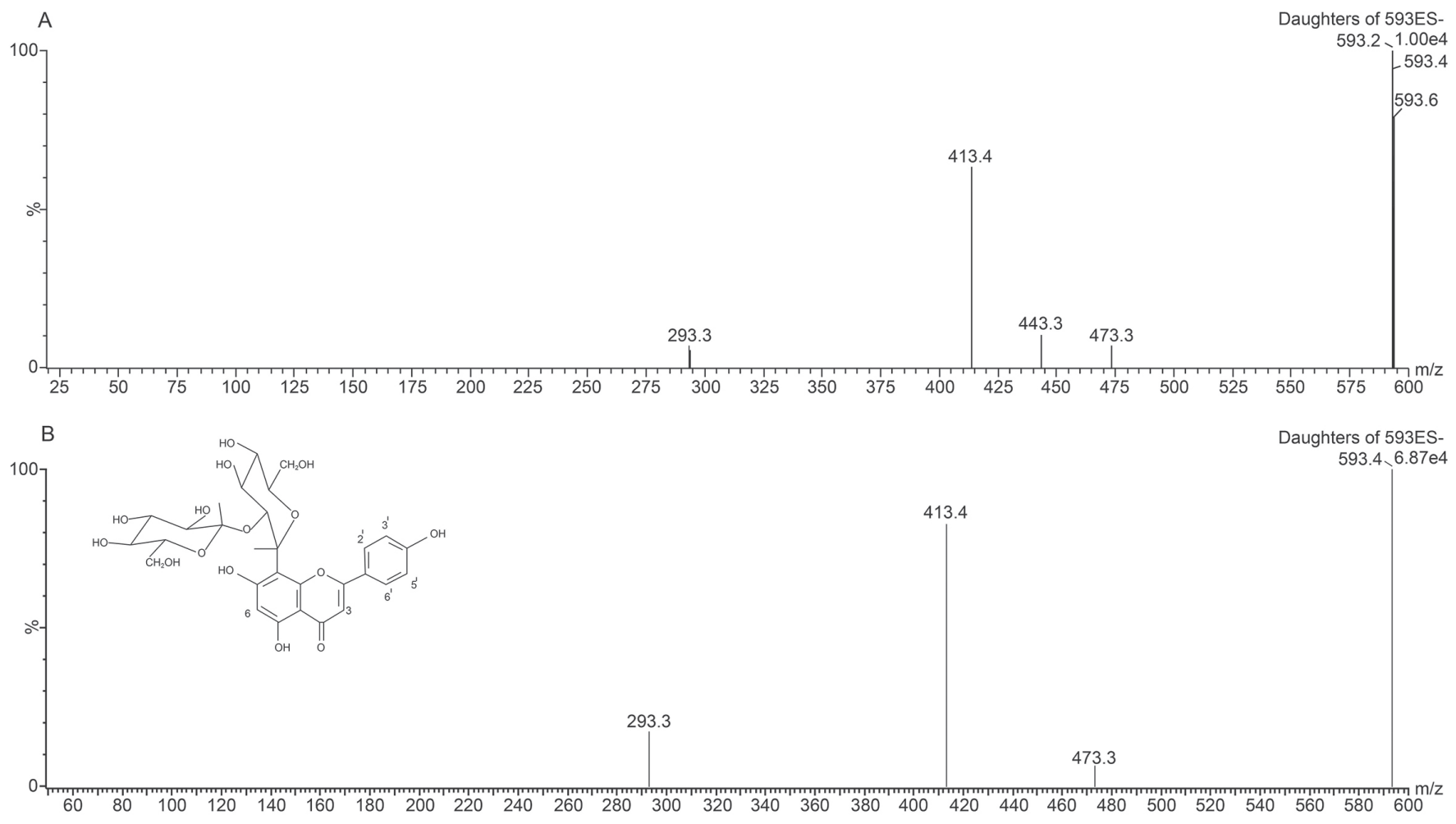

FIGURE 4 - ESI(-)-MS/MS. A) Fragmentation of peak $593 \mathrm{~m} / \mathrm{z}$ of P. coccinea (Aubl.) methanolic extract. B) Fragmentation of 2 "--O- $\beta$-D-glucopyranosyl-vitexin. For conditions, see material and methods. 

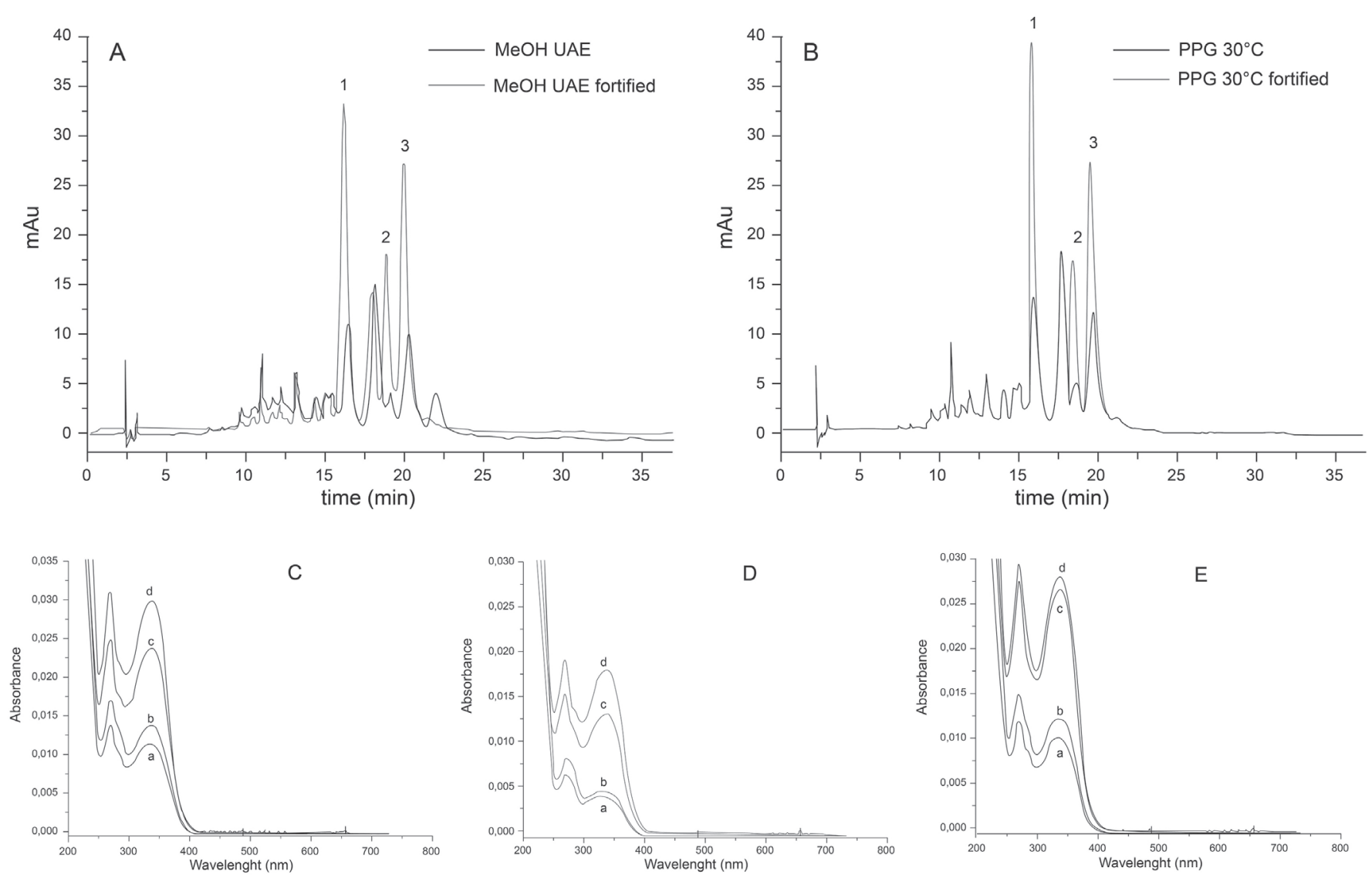

FIGURE 5 - Chromatograms identifying the three flavonoids found in $P$. coccinea (Aubl.). A) Chromatogram of UAE methanolic extract. B) Chromatogram of the glycolic extract obtained by $72 \mathrm{~h} 30^{\circ} \mathrm{C}$ maceration. $1: 2$ "-O- $\beta$-D-glucopyranosyl-vitexin; 2: vitexin; 3: isovitexin. C) DAD spectral data of peak 1. D) DAD spectral data of peak 2. E) DAD spectral data of peak 3. a: glycolic extract; b: fortified glycolic extract; c: methanolic extract; $d$ : fortified methanolic extract.
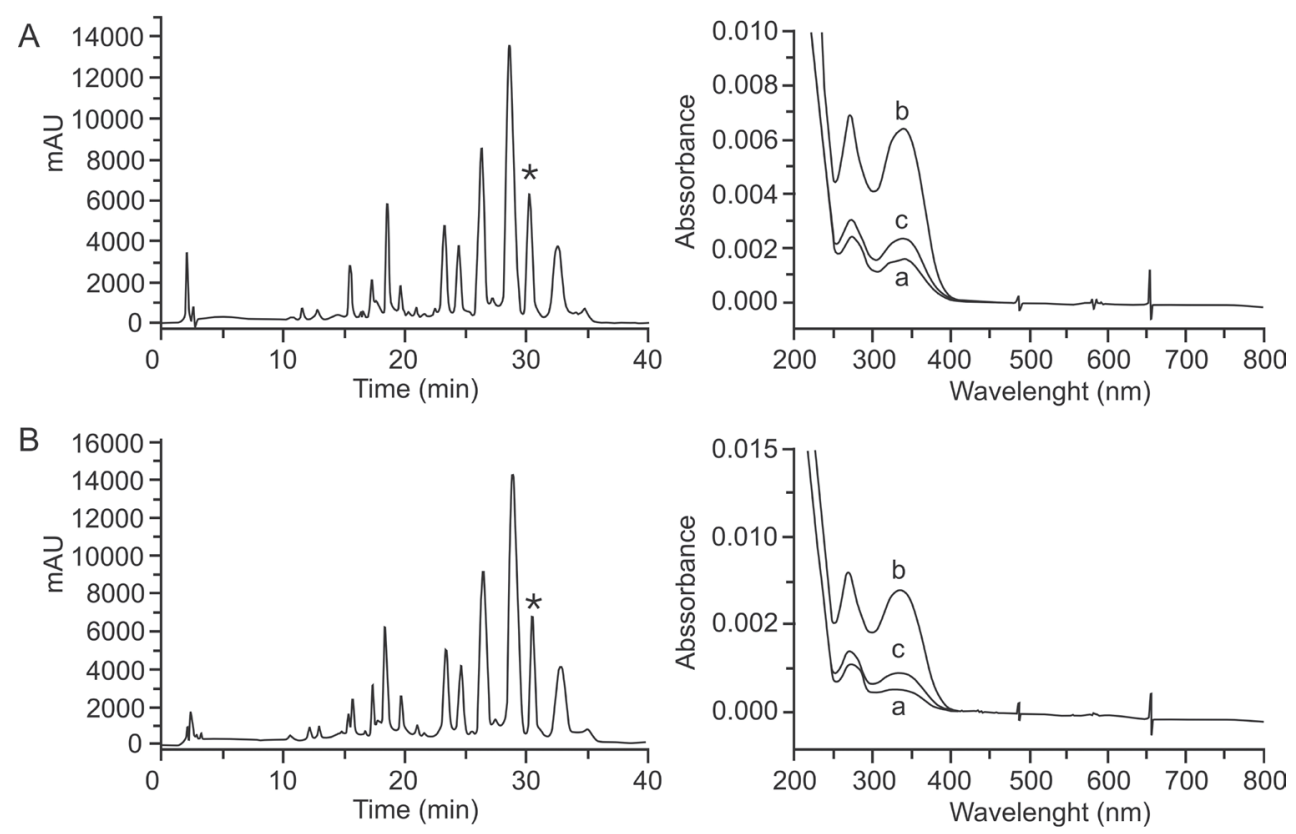

FIGURE 6 - A) Left: chromatogram of the methanolic extract. Isovitexin peak is marked with a $(*)$. Right: spectra of isovitexin peak at the (a) beginning (b) top and (c) end. B) Left: chromatogram of the glycolic extract. Isovitexin peak is marked with a $(*)$. Right: spectra of isovitexin peak at the (a) beginning (b) top and (c) end. 
TABLE II - Analytical curves parameters

\begin{tabular}{lcccccc}
\hline Sample & Slope & Slope SD* & Intercept & Intercept SD* & $\mathrm{r}^{2}$ & $\begin{array}{c}\text { Correlation } \\
\text { coefficient (r) }\end{array}$ \\
\hline Methanolic extract & 21653 & 265 & 74210 & 3254 & 0.99790 & 0.999 \\
Glycolic extract & 18146 & 484 & 169726 & 6101 & 0.99084 & 0.995 \\
Standard isovitexin & 21252 & 330 & 995 & 4157 & 0.99688 & 0.998 \\
\hline
\end{tabular}

*Estimative of the absolute standard deviation

TABLE III - Recovery, extraction efficiency and repeatability of the method

\begin{tabular}{lcccccc}
\hline Extract & \multicolumn{3}{c}{ Methanolic extract } & \multicolumn{3}{c}{ Glycolic extract } \\
\hline Concentration $\left(\mu \mathrm{g} \mathrm{L}^{-1}\right)$ & 1 & 10 & 20 & 1 & 10 & 20 \\
Recovery $(\%)$ & $79 \pm 4$ & $104 \pm 6$ & $102 \pm 4$ & $89 \pm 6$ & $98 \pm 3$ & $96 \pm 0.4$ \\
Extraction efficiency(\%) & 95 & - & 97 & 93 & - & 96 \\
Repeatability (RSD*) & 0.9 & 4 & 3 & 0.6 & 2 & 0.3 \\
\hline
\end{tabular}

*Relative standard deviation

confirmed by ANOVA $(p>0.5)$. Table II lists the analytical curve parameters.

From the observation of the slopes in Table II, it is possible to observe the presence of a matrix effect in both extracts. In numbers, the matrix effect corresponds to a $1.89 \%$ isovitexin signal suppression in the methanolic extract and to a $14.61 \%$ signal increase in the glycolic one. These results revealed that the matrix effect is expressive at $95 \%$ of confidence and, thus, the choice of standard addition method was appropriate for the quantification of isovitexin in these extracts.

By the validated method, it could be found that the UAE $P$. coccinea methanolic extract had $2.28 \pm 0.06 \mathrm{mg}$ of isovitexin per gram, while the amount of the same compound in the glycolic extract obtained by $30{ }^{\circ} \mathrm{C}$ maceration was of $0.18 \pm 0.01 \mathrm{mg} \mathrm{g}^{-1}$. The recovery of the extraction method was within the range of 70 to $120 \%$ and the SPE process led to extraction efficiencies higher than $93 \%$, indicating that almost all the isovitexin present in the samples could be extracted in the sample preparation step developed in this work (Table III). Therefore, the quantity of isovitexin could be reliably determined in both extracts.

Finally, it can be inferred that, even though $P$. coccinea did not show direct photoprotective properties, the observed antioxidant activity gives perspective for the use of this plant in topical cosmetic formulations. While the glycolic $P$. coccinea extract presented the lowest antioxidant activity, the methanolic extracts behavior allows us to conclude that propylene glycol was not able to provide the best extraction of the antioxidant compounds from the plant material under the evaluated methods, requiring further optimization or the evaluation of new strategies for the extract preparation. The quantity of isovitexin indicates that the difference between the antioxidant activity of the methanolic and glycolic extracts may be due to the concentration of the bioactive compounds. However, aside from the different extraction power under the evaluated circumstances, it could be noticed that methanol and propylene glycol presented comparable selectivity for the polyphenols from $P$. coccinea, since the extracts exhibited similar chromatographic profiles and the compounds 2 "-O- $\beta$ D-glucopyranosyl-vitexin, vitexin and isovitexin were identified in both of them.

\section{ACNOWLEDGEMENTS}

The Brazilian agencies CNPq (307101/2011-8 and 573672/2008-3), FAPESP (2008/57805-2) and CAPES (23038.030241/2008-17) are gratefully acknowledged for providing financial support to this research. Special thanks to Rita de Cassia Z. Souza and Dr. Fabio Gozzo for their help with the mass spectrometry analyses, Claudia Martelli for the help with the spectrophotometric assays, Dr. Marcelo C. Dornelas for the plant material, Dr. Caroline C. Lourenço for ORAC-FL test training, Consulfarma, specially Cleber Barros, for formulating the topical emulsion, and Jéssica C. Silva for the image support. 


\section{REFERENCES}

Afaq F. Natural agents: cellular and molecular mechanisms of photoprotection. Arch Biochem Biophys. 2011;508(2):144-151.

Argentieri MP, Levib M, Guzzob F, Avatoa P. Phytochemical analysis of Passiflora loefgrenii Vitta, a rich source of luteolinderived flavonoids with antioxidant properties. J Pharm Pharmacol. 2015;67(11):1603-1612.

Barreira JCM, Pereira E, Duenas M, Carvalho AM, SantosBuelgab C, Ferreira ICFR. Bryonia dioica, Tamus communis and Lonicera periclymenum fruits: Characterization in phenolic compounds and incorporation of their extracts in hydrogel formulations for topical application. Ind Crops Prod. 2013;49:169-176.

Basf Sunscreen Simulator ${ }^{\mathrm{TM}}$. [citado 01 Out 2017]. Available at: https://www.sunscreensimulator.basf.com/Sunscreen Simulator/Login_show.action.

Brasil. Agência Nacional de Vigilância Sanitária (ANVISA). Guia de Estabilidade de Produtos Cosméticos. 2004. Available at: http://bvsms.saude.gov.br/bvs/publicacoes/cosmeticos.pdf.

Correa MP. Dicionário das Plantas Úteis do Brasil e das Exóticas Cultivadas, Ministério da Agricultura, Instituto Brasileiro de Desenvolvimento Florestal: Rio de Janeiro, Brasil; 1984.

Dahuan K, Dahuan S, Sharma A. Passiflora: a review update. J Ethnopharm. 2004;94(1):1-23.

Economou A, Botisti H, Antoniou S, Tsipi D. Determination of multi-class pesticides in wines by solid-phase extraction and liquid chromatography-tandem mass spectrometry. J Chrom A. 2009;1216(31):5856-5867.

Ferreres F, Sousa C, Valentão P, Andrade, PB, Seabra RM, GilIsquierdo A. New C-Deoxyhexosyl flavones and antioxidant properties of Passiflora edulis leaf extract. J Agric Food Chem. 2007;55(25):10187-10193.

Gonzales S, Fernandes-Lorente M, Gilaberte-Calzada Y. The latest on skin photoprotection. Clin Dermatol. 2008;26(6):614626.

Huang W, Xue A, Niu H, Jia Z, Wang J. Optimised ultrasonicassisted extraction of flavonoids from Folium eucommiae and evaluation of antioxidant activity in multi-test systems in vitro. Food Chem. 2009;114(3):1147-1154.
Ignat I, Volf I, Popa VI. A critical review of methods for characterisation of polyphenolic compounds in fruits and vegetables. Food Chem. 2011;126(4):1821-1835.

International Conference on Harmonisation (ICH). Validation of Analytical Procedures: Methodology, Q2B (CPMP/ ICH/281/95); 2005.

Jiang X, Meng Y, Liang Y, Xiao Z. Evaluation of the antioxidant and antibacterial activities of various solvent extracts from Passiflora wilsonii Hemsl. Biotechnology. 2015;14(3):129-135.

Mansur JS, Breder MNR, Mansur MCA, Azulay RD. Determinação do fator de proteção solar por espectrofotometria. An Bras Dermatol.1986;61(3):121-124.

Masteikova R, Bernatoniene J, Bernanoniene R, Velziene S. Antiradical activities of the extract of Passiflora incarnata. Acta Pol Pharm. 2008;65(5):577-583.

Mensor LL, Menezes FS, Leitão GG, Reis AS, dos Santos $\mathrm{TC}$, Coube CS, et al. Screening of Brazilian plant extracts for antioxidant activity by the use of DPPH free radical method. Phytother Res. 2001;15(2):127-30.

Müller SD, Vasconcellos SB, Coelho M, Biavatti, MW. LC and UV determination of flavonoids from Passiflora alata medicinal extracts and leaves. J Pharm Biom Anal. 2005;37(2):399-403.

Paniwynk L, Cai H, Albu S, Mason TJ, Cole R. The enhancement and scale up of the extraction of anti-oxidants from Rosmarinus officinalis using ultrasound. Ultrasound Sonochem. 2009;16(2):287-292.

Pereira CAM, Yariwake JH, McCullagh M. Distinction of the C-glycosylflavone isomer pairs orientin/isoorientin and vitexin/ isovitexin using HPLC-MS exact mas measurement and insource CID. Phytochem Anal.2005;16(5):295-301.

Ramaiya SD, Bujang JS, Zakaria MH. Assessment of total phenolic, antioxidant, and antibacterial activities of Passiflora species. Sci. World J. 2014;2014:167309.

Reginatto FH, De-Paris F, Petry RD, Quevedo J, Ortega GG, et al. Evaluation of anxiolytic activity of spray dried powders of two south brazilian Passiflora species. Pytother Res. 2006;20(5):348-351. 
Rudinicki M, Oliveira MR, Pereira TV, Reginatto FH, DalPizzol F, Moreira JCF. Antioxidant and antiaglycation properties of Passiflora alata and Passiflora edulis extracts. Food Chem. 2007;100(2):719-724.

Sakalem ME, Negri G, Tabach R. Chemical composition of hydroethanolic extracts from five species of the Passiflora genus. Braz J Pharmacog. 2012;22(6):1219-1232.

Salvador MJ, Ferreira EO, Mertens-Talcott SU, de Castro WV, Butterweck V, Derendorf H, et al. Isolation and HPLC quantitative analysis of antioxidant flavonoids from Alternanthera tenella Colla. Z Naturforsch. 2006;61(1-2):19-25.

Silva GC, Bottoli CBG. Analyses of Passiflora compounds by chromatographic and electrophoretic techniques. Critical Rev Anal Chem. 2015;45(1):76-95.

Silva JK, Cazarin CBB, Colomeu TC, Batista AG, Meletti LMM, Paschoal JAR, et al. Antioxidant activity of aqueous extract of passion fruit (Passiflora edulis) leaves: in vitro and in vivo study. Food Res Int. 2013;53(2):882-890.

Siqueira SRR, Donato JL, Nucci G, Reyes FGR. A highthroughput method for determining chloramphenicol residues in poultry, egg, shrimp, fish, swine and bovine using LC-ESI-MS/ MS. J Sep Sci. 2009;32(23-24):4012-4019.

Spencer K, Seigler DS. Passicoccin: a sulphated cyanogenic glycoside from Passiflora coccinea. Phytochemistry. 1985;24(11):2615-2617.
Stalikas CD. Extraction, separation and detection methods for phenolic acids and flavonoids. J Sep Sci. 2007;30(18):32683295.

Velasco MVR, Sarruf FD, Salgado-Santos, IMD, HaroutiounianFilho CA, Kaneko T, Baby AR. Broad spectrum bioactive sunscreens. Int J Pharm. 2008;363(1-2):50-57.

Vilkhu K, Mawson R, Simins L, Bates D. Applications and opportunities for ultrasound assisted extraction in the food industry - A review. Innovative Food Sci Emerg Technol. 2008;9(2):161-169.

Xiao W, Han L, Shi B. Microwave-assisted extraction of flavonoids from Radix astragali. Sep Purif Technol. 2008;62(3):614-618.

Zeraik ML, Pereira CAM, Zuin VG, Yariwake JH. Maracujá: um alimento funcional? Braz J Pharmacogn. 2010a;20(3):459-471.

Zeraik ML, Yariwake JH. Quantification of isoorientin and total flavonoids in Passiflora edulis fruit pulp by HPLC-UV/DAD. Microchem J. 2010b;96(1):86-91.

Zillich OV, Schweiggert-Weisz U, Eisner P, Kerscher M. Polyphenols as active ingredients for cosmetic products. Int $\mathrm{J}$ Cosmetic Sci. 2017;37(5):455-464.

Received for publication on $05^{\text {th }}$ November 2017 Accepted for publication on $17^{\text {th }}$ October 2018 